\title{
Design and implementation of an S-band transmitter for nanosatellites with new configuration
}

\author{
Bui Thi Ha ${ }^{1,2}$, Tran Chinh Doan ${ }^{1}$, Bach Gia Duong ${ }^{1}$ \\ ${ }^{1}$ Faculty of Electronics and Telecommunication, Vietnam National University, Hanoi, Vietnam \\ ${ }^{2}$ Department of Space Research and Development, Vietnam National Space Center, Hanoi, Vietnam
}

\begin{tabular}{l} 
Article Info \\
\hline Article history: \\
Received Aug 19, 2021 \\
Revised Nov 23, 2021 \\
Accepted Dec 1, 2021 \\
\hline Keywords: \\
Frequency synthesizer \\
Nanosatellite \\
Power amplifier \\
S-band \\
Transmitter
\end{tabular}

\section{Corresponding Author:}

Bui Thi Ha

Department of Space Research and Development, Vietnam National Space Center

18 Hoang Quoc Viet, Cau Giay, Hanoi, Vietnam

Email: btha@vnsc.org.vn

\begin{abstract}
In this paper, the author presents the design and implementation of an Sband transmitter for nanosatellites. By combining heterostructure field effect transistors (HFET) and laterally diffused metal-oxide-semiconductor (LDMOS) technology and using flexible structure and flexible control method, this research obtained $60 \mathrm{~dB}$ gain power when input is $-14 \mathrm{dBm}$, output power is $46 \mathrm{dBm}$ (more than $25 \mathrm{~W}$ ) in $2,1 \mathrm{GHz}-2,3 \mathrm{Ghz}$ frequency; phase noise is $-80 \mathrm{dBc} / \mathrm{Hz}$ at $100 \mathrm{KHz}$ offset frequency. Unlike other traditional transmitters, this transmitter was designed with multi-stages which have multi-peaks resonance to expand bandwidth to respond to the requirement of generation of the complex signal in wide band. Moreover, the phase locked loop (PLL) in frequency synthesizer makes the frequency conversion more flexible and output frequency more stable; thermal problem in module also was solved by using thermistor and operation mode. Measurement results prove that the design does not only satisfy the requirements of nanosatellites but also can be applied to other satellites together with their ground station because it has open configure with flexible structure and flexible control method.
\end{abstract}

This is an open access article under the CC BY-SA license.

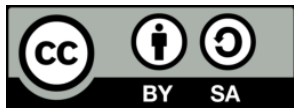

\section{INTRODUCTION}

Nowadays, all over the world, space technology has been widely taught, researched, developed in universities, academic institutes, companies. Space technology is applied for various areas such as communication, earth observation, forest and agricultural management, marine and land management, natural resources and territorial management. In general, it plays an important role for development of society and economy as well as national security of a country. Satellite is a part of this field. Many organizations are interested in researching, designing and manufacturing satellite, particularly in small satellites because of low manufacturing cost, low launching cost and suitable for researching and testing. Moreover, these satellites satisfy the most of the requirements of the users because of their safety and reliability. Besides, these satellites can be designed support each other in one small satellite constellation to meet the mission requirements. Small satellite mass is lower than $200 \mathrm{~kg}$. Nanosatellite is a small satellite of which mass is from 1 to $10 \mathrm{~kg}$. This research is able to apply for nanosatellite named NanoDragon (Vietnamese satellite).

The satellite consists of seven subsystems: Payload subsystem, structure subsystem, thermal, attitude determination and control subsystem, command and data handling subsystem, electrical power subsystem and communication subsystem (COM). All of subsystems are very important. This research focuses on communication subsystem. Without COM, the satellite will not able to work properly because 
communication subsystem provides the interface between satellite and ground station. Communication subsystem of satellite consists of transmitter and receiver. This system is illustrated in the Figure 1.

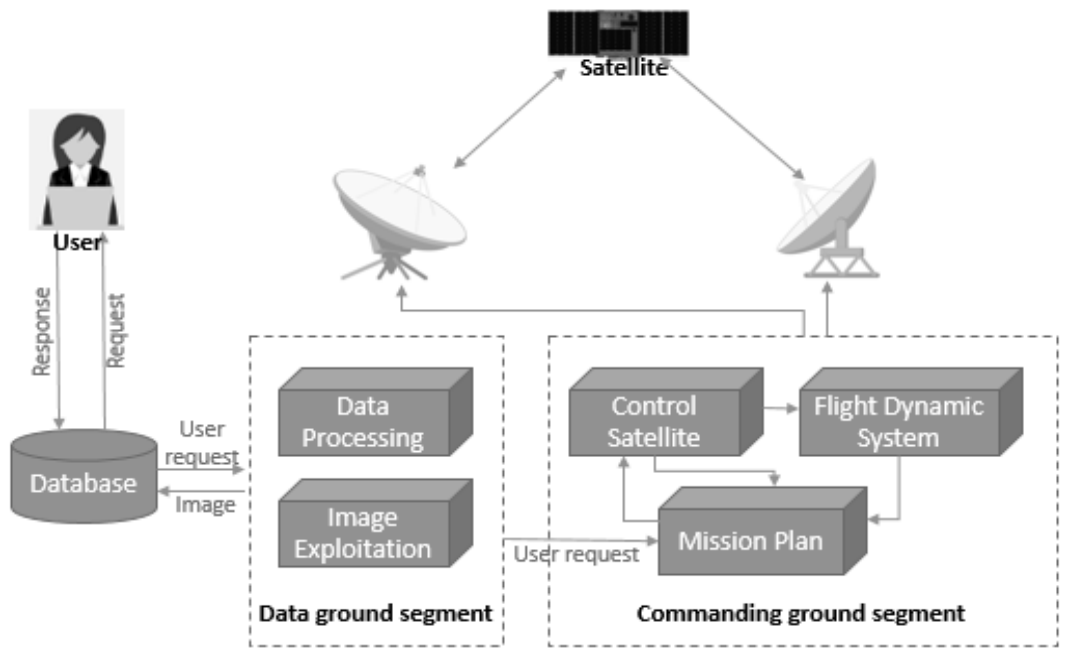

Figure 1. Communication subsystem [1]

Transmitter was researched, designed and manufactured many years ago. The transmitter is good if it has good parameters, such as: high-performance addressing (HPA) performance, converter performance, and frequency stability. Depending on purpose and requirement of user such as: weight, size, volume, budget, orbit, altitude, lifetime or payload of satellite, each transmitter was designed to satisfy these requirements [1]-[25]. These transmitters focused on solving problems: survey and compare result of method approaches [5], [6], effect of environment to this module [2], increase bandwidth [5], [11], [14], [21], increase power output [7], [16], decrease cost [3], approach very high speed integrated circuit (VHSIC) hardware description language (VHDL) in modulator [15]. Recently, variety of transmitter approached multi-stages power amplifier [11][13], [22], [23], or using Wilkinson power combiner method [7], [10], using technology in transmitter architecture [17] to increase power output. However, these designs have low reliability and only apply to a permanent system.

In order to solve those problems, the paper focuses on design transmitter module which can not only increase output power with large bandwidth (by using multi-stages, multi-peaks resonance in power amplifier), but also solve stability of output frequency (by using phase locked loop (PLL) structure in frequency synthesizer) and stability of thermal in module (by using thermistor in amplifier combined with operation mode with small polarization power dissipation) and flexibility with flexible control based on open-configure. This highlight helps transmitter to be easier to improve its function and apply to other systems. By using heterostructure field effect transistors (HFET), laterally diffused metal-oxidesemiconductor (LDMOS) technology and combination of flexible control method in frequency synthesizer, transmitter obtains $60 \mathrm{dBm}$ gain power, phase noise $-80 \mathrm{dBc} / \mathrm{Hz}$ at $100 \mathrm{KHz}$ offset frequency, high linearity, and high stability.

\section{DESIGN AND SIMULATION}

\subsection{Frequency synthesizer}

Frequency synthesizer was designed with voltage-controlled oscillator (VCO) combined PLL. The PLL helps to increase quality of generated signal, decrease noise, and flexible of system. The PLL used ADF4113 and AT89C51 microcontroller. The advances of this module are: data are inputted from keyboard; information is displayed by liquid crystal display (LCD). The block diagram of frequency synthesizer is shown in Figure 2.

Signal from temperature compensated crystal oscillator (TCXO) go to ADF4113. ADF4113 is connected to AT89C51 to change the output frequency of frequency synthesizer. Data from keyboard was displayed on LCD monitor. The schematic of frequency synthesizer is shown in Figure 3. 


\begin{tabular}{|c|c|c|c|}
\hline Convert function & Pulse & TCXO & \\
\hline Keyboard & Micro-controller & ADF4113 & 7 \\
\hline & LCD & Ampli & VCO \\
\hline
\end{tabular}

Figure 2. Block diagram of frequency synthesizer

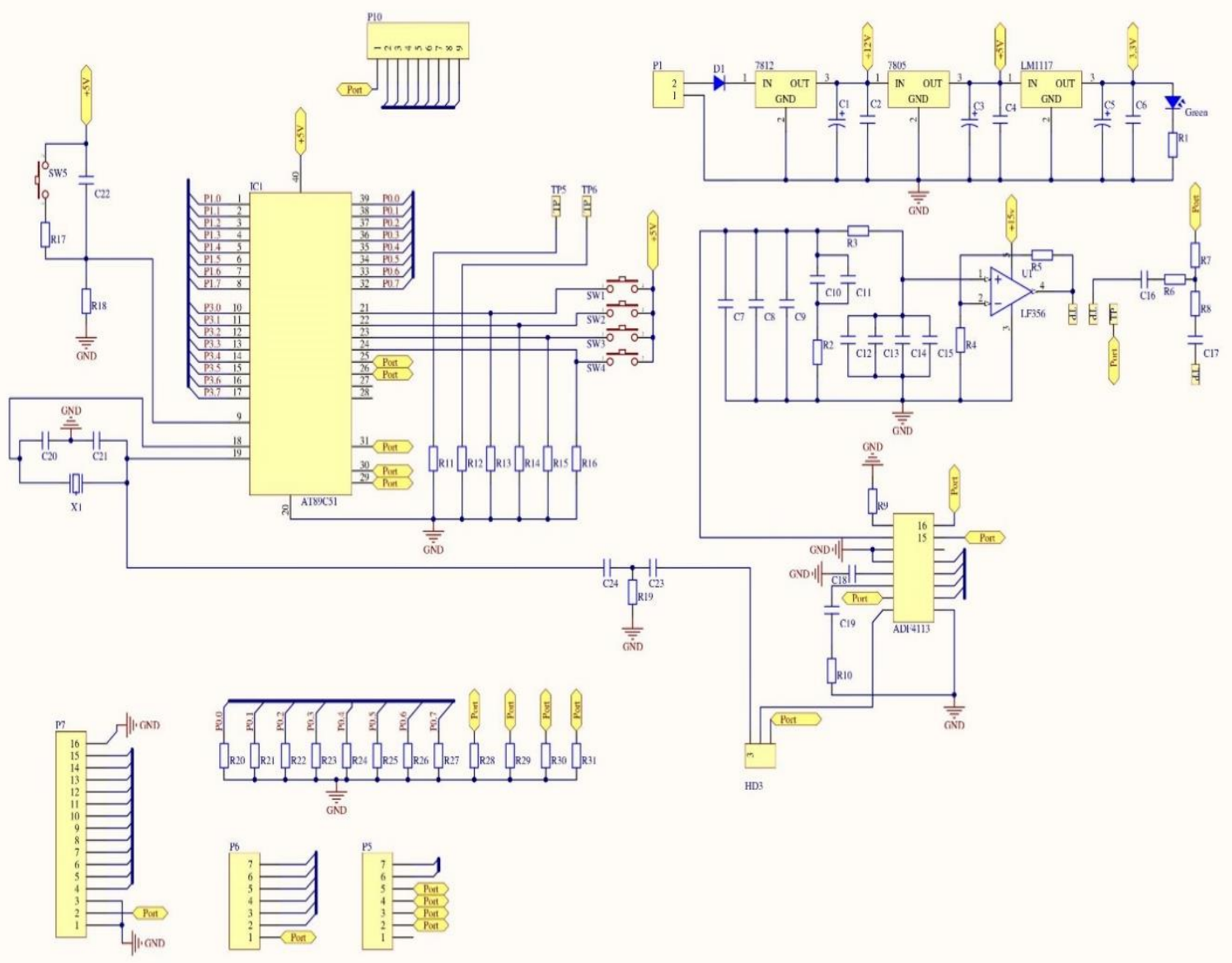

Figure 3. The schematic of the frequency synthesizer

Stander frequency from TCXO goes to IC ADF4113. Microcontrol AT89C51 of ATMEL is connnected to IC ADF4113 for changing gennerate frequency of frequency sybthesizer. After receiving control frequency code, the IC ADF4113 generate curent on CP (pin 2). This current through resister goes to filter (RC), then goes to amplifier using IC LF 356 for converting voltage control VCO of which value sastifies required frequency.

\subsection{Design of BPSK modulator}

Before the signal is transmitted from ground station to satellite or from satellite to ground station, it must be modulated. The binary phase-shift keying (BPSK) has excellent bit error rate (BER) performance, fast transfer rates, and low complexity. The BPSK finds applications in weak signal communication spread spectrum and radar system. These factors make BPSK be one of the main modulation modes of communication subsystem of satellite.

In a BPSK modulation scheme, the phase of the carrier is shifted by $180^{\circ}$ for one data symbol. There are many different modulation methods. Each modulation method has different advantages and different disadvantages and suitability with the system. To satisfy the requirement of Vietnamese satellite requirements, obtain high accuracy, low attenuation, low budget, easily fabricate and easily integrate with other device; the authors decided to use the HMC208MS8. Inside HMC208MS8, there are 8 lead plastic surface mount mini small outline package (MSOP). This chip is constructed of GaAs Schottky diodes and 
novel planar transformer baluns on the chip. Moreover, HMC208MS8 is the smallest footprint $(3.00 \times 4.9$ $\mathrm{mm})$ and thinest $(1.00 \mathrm{~mm})$ available for a complete modulator. Conversion loss is shown in Figure 4.

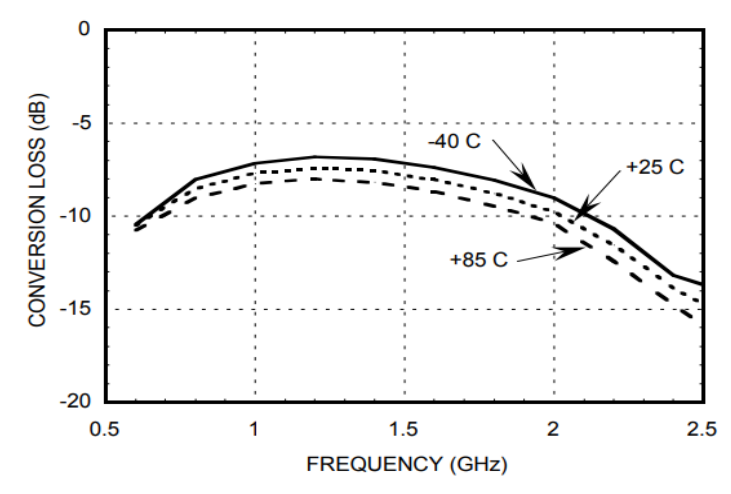

Figure 4. Conversion loss of HMC208MS8 [8]

This modulator is designed based on the double balanced modulator idea. The using GaAs Schottky diodes in ring modulator is an innovative design. Because Schottky diodes have the reverse recovery time when the diode switches from the conducting to the non-conducting state, which the other diodes don't have. With Schottky diodes, switching is essentially instantaneous. The switching time is about 100 ps or tens of nanoseconds. Hence, this type of diode is suitable for RF circuit. Just with a HMC208MS8 chip, we had modulator circuit above.

This BPSK modulator with directly high frequency input was designed, fabricated and presented, published in "the $13^{\text {th }}$ International Conference on Advanced Technologies for Communication" with title "design, fabrication transmitter modulator at S-band for Microsatellite with the direct RF input" [8]. The Figures 5 and 6 show board design BPSK modulator, which was fabricated on RF-4 PCB material.

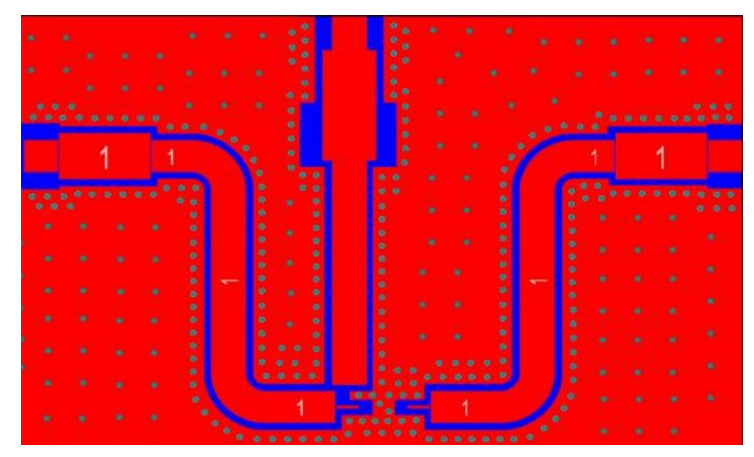

Figure 5. The design board of BPSK

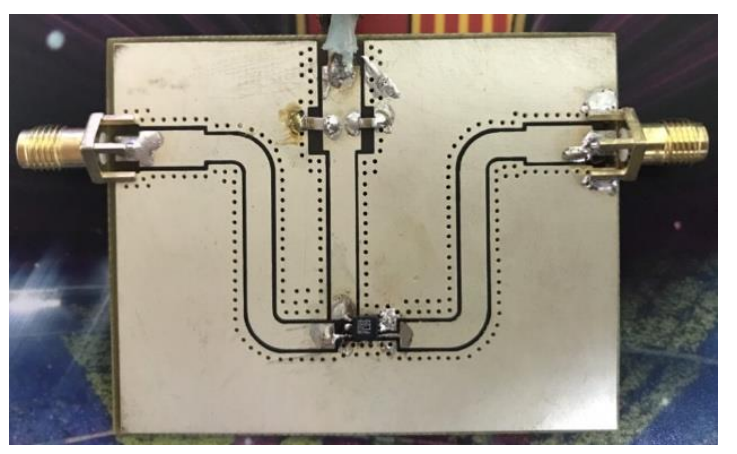

Figure 6. Fabricated BPSK modulator

\subsection{Design of power amplifier module}

The power amplifier module consists of two stages. There is a pre-amplifier using SHF-0589 device and main amplifier using Wilkinson bridge with BLM7G1822S device. A stability thermal method is applied in pre-amplifier stage and main power amplifier stage by preventing source of heat. The thermistor is attached in output. The signal output of thermistor goes back and controls the amplifying coefficient. In addition, pre-amplifier stage works in $\mathrm{AB}$ mode and main power amplifier works in $\mathrm{C}$ mode. By using BLM7G1822S in main power amplifier stage is a dual section, 2-stage power monolithic microwave integrated circuit (MMIC), so can use push-pull amplifier combine the Wilkinson bridge, operate at C mode. With this operation mode, power dissipation is very small. So, thermal in module is stabilized.

The first stage used the SHF-0589-is a high-performance GaAs HFET, The HFET technology improves breakdown voltage while minimizing Schottky leakage current resulting in higher PAE and improved linearity. This power pre-amplifier provides high output power and impedance matching with the 
fore-and-aft circuit of this module. By using SHF-0589 device combined with silicon germanium heterostructure bipolar transistor amplifier (SGA) in module, its power output obtained around $23.5 \mathrm{dBm}$.

The output power of power amplifier module also depends on the input/output matching, supply voltage and supply current. Therefore, the impedance matching with output of BPSK modulator and input of antenna are necessary. By using advanced design system (ADS) software with permeability Mur=1, conductor thickness $\mathrm{T}=0.035$, dielectric constant $\mathrm{Er}=4.4$. The authors have designed impedance matching in input and output. The schematic of impedance matching of input and its simulation result were presented in Figures 7 and 8 .

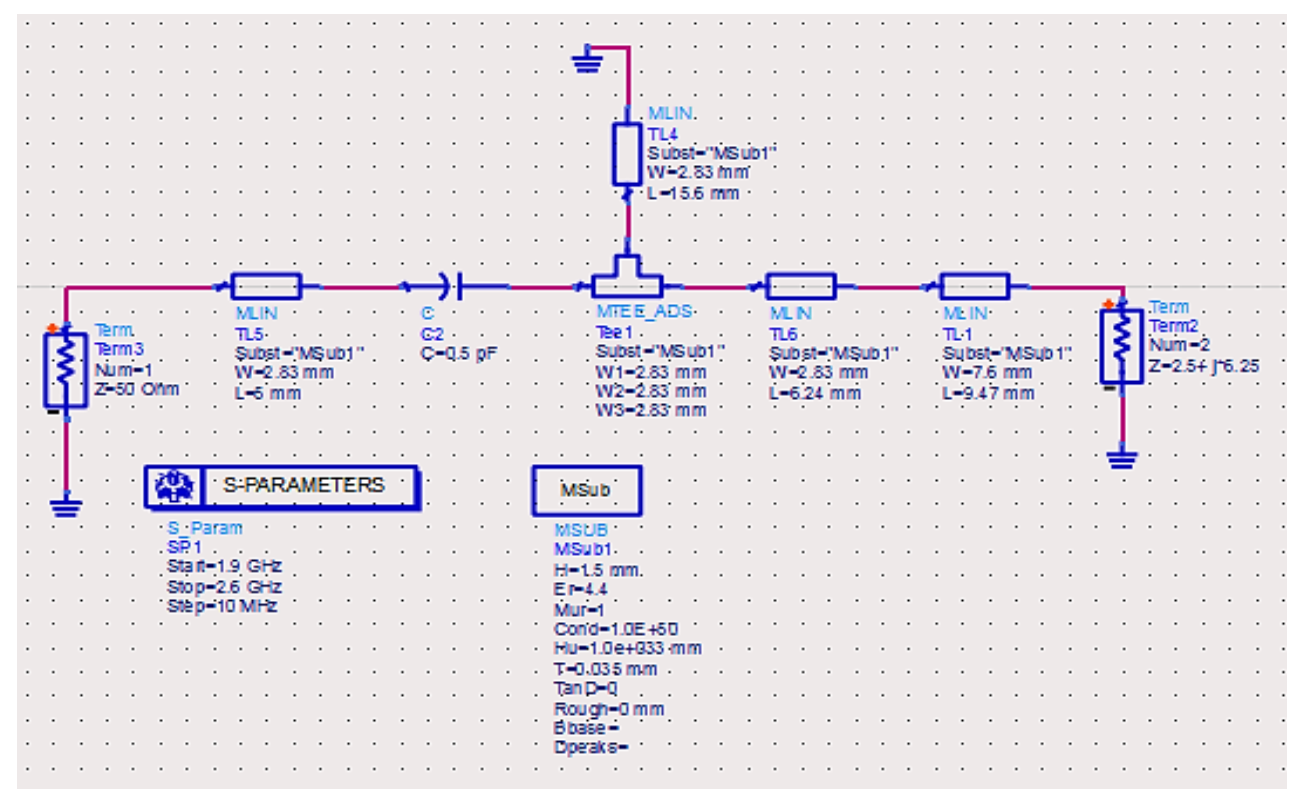

Figure 7. The schematic of impedance matching in input pre-amplifier stage

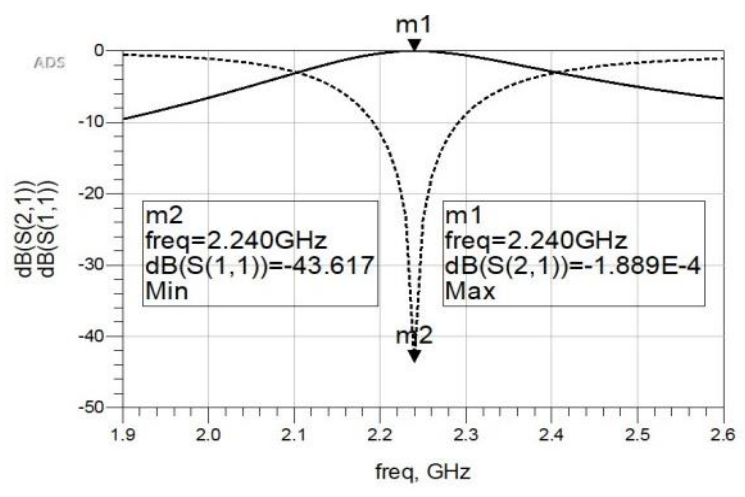

Figure 8. Simulation result of input pre-amplifier stage

The schematic of impedance matching of input branch and its simulation results are presented in Figures 9 and 10. The main power amplifier module used the Wilkinson bridge method. This module consists of two branches; each branch used a BLM7G1822S. The BLM7G1822S is a dual section, two stages power MMIC using Ampleon's state of the art GEN 7LMMOS technology. The LDMOS technology is a lateal double-diffused MOS transistor technology. Moreover, this device has integrated electrostatic discharge (ESD) protection. ESD is an important problem in the safety of the equipment. This function is very importance in the safety of the equipment and operating of it in orbit.

The schematic of impedance matching network of output main amplifier and its simulation result was illustrated in Figures 11 and 12. The Figure 12 shows S11 parameter (input reflection coefficient) is $-10.907 \mathrm{~dB}$ at $1.96 \mathrm{GHz},-52.424 \mathrm{~dB}$ at $2.2 \mathrm{GHz}$ and $-10.38 \mathrm{~dB}$ at $2.44 \mathrm{GHz}$. These results are acceptable. The Figure 13 presented the fabricated power amplifier module. 


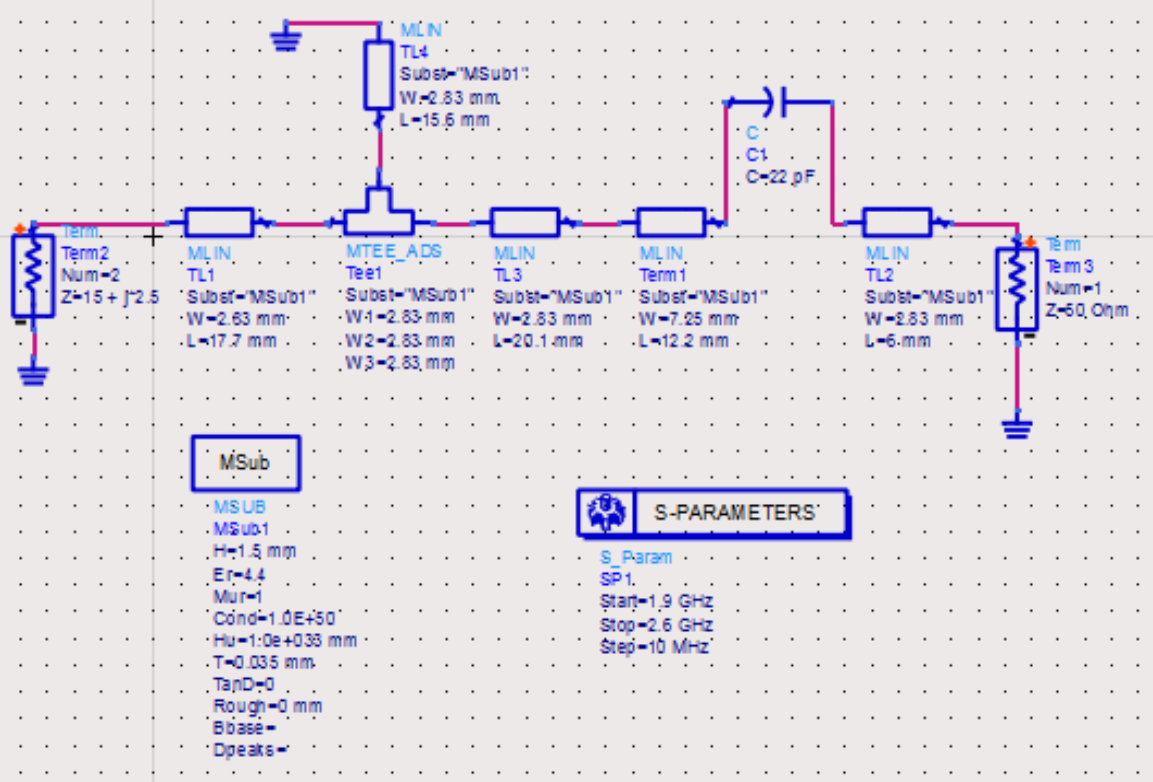

Figure 9. The schematic of impedance matching in output pre-amplifier stage

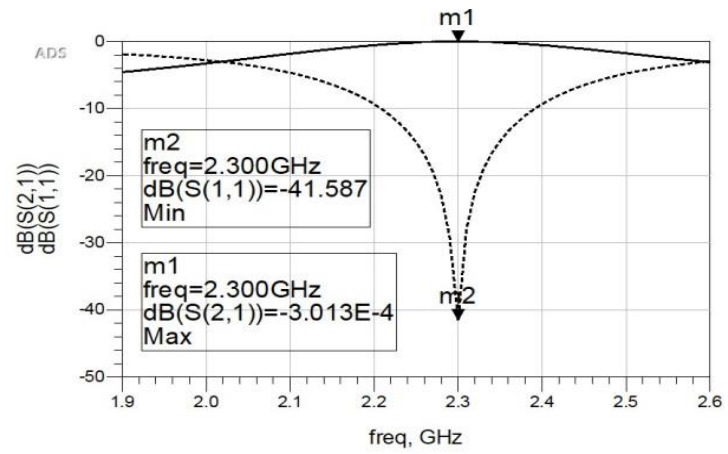

Figure 10. Simulation result of output pre-amplifier stage

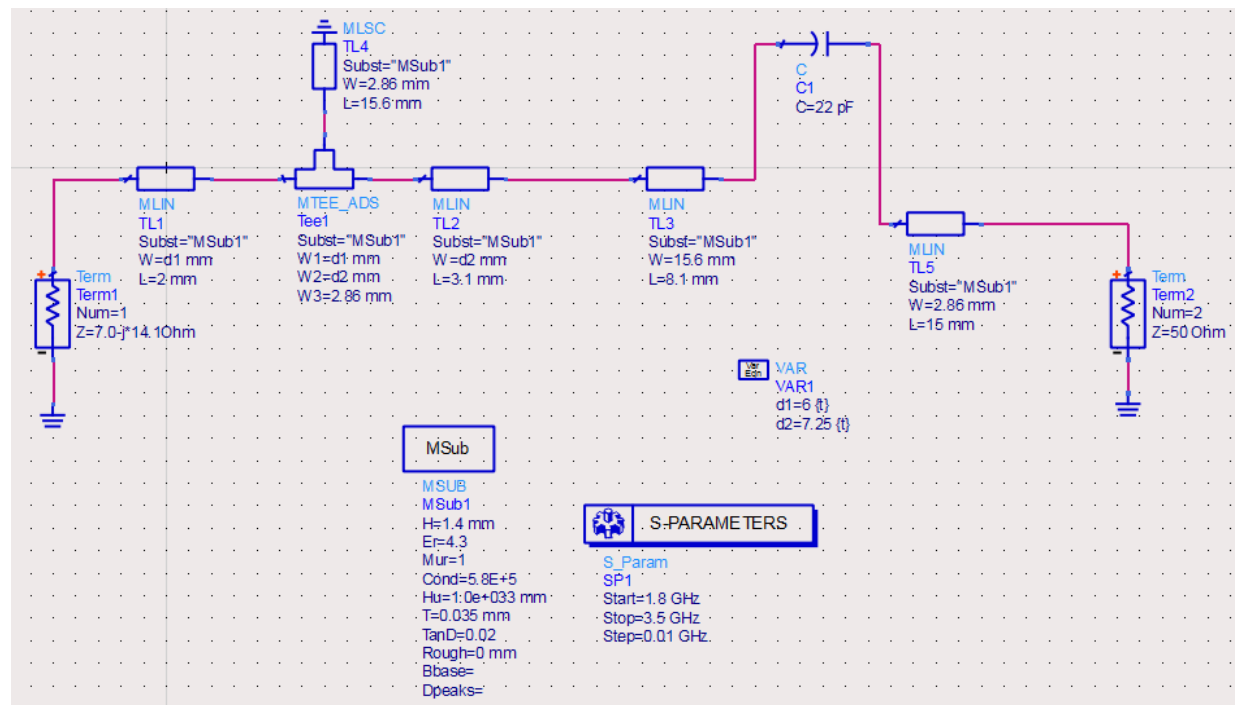

Figure 11. The schematic of impedance matching in output branch 


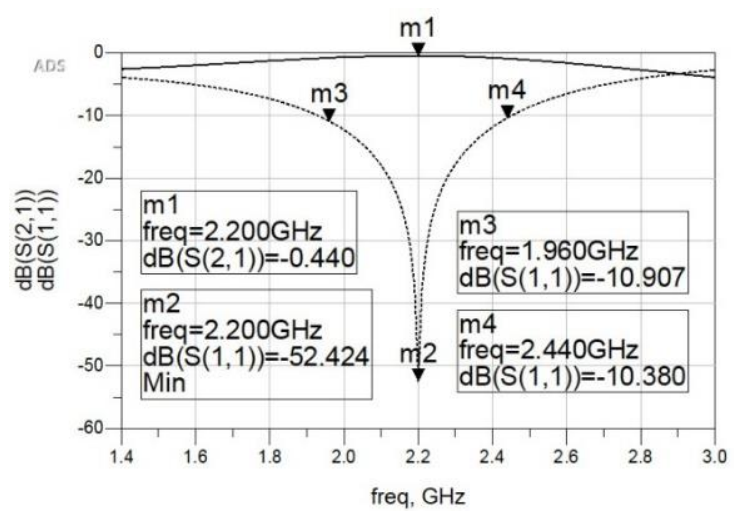

Figure 12. Simulation result of impedance matching output

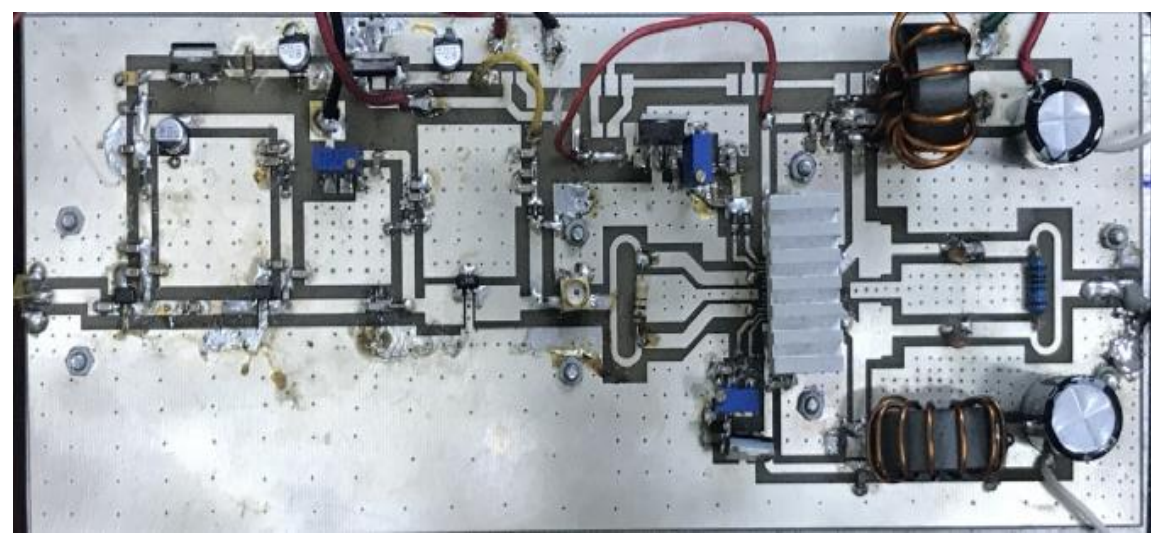

Figure 13. The fabricated power amplifier module

\section{RESULTS AND DISCUSSION}

\subsection{BPSK modulator}

Measurement results of BPSK modulator are shown in the Figures 14 and 15. Compare with measurement result in Figure 15 and conversion loss in Figure 4, we see conversion loss in fabricated circuit of BPSK modulator from $3 \mathrm{~dB}$ to $5 \mathrm{~dB}$ in $2.1-2.3 \mathrm{GHz}$ frequency. This result demonstrates that this BPSK modulator is good, impedance matching well and high accuracy fabrication circuit.

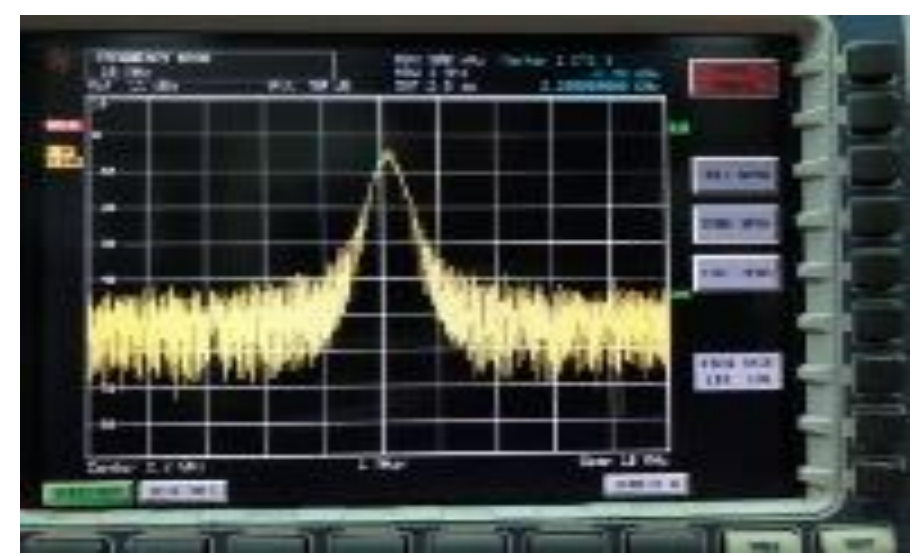

Figure 14. Measurement of BPSK modulator 


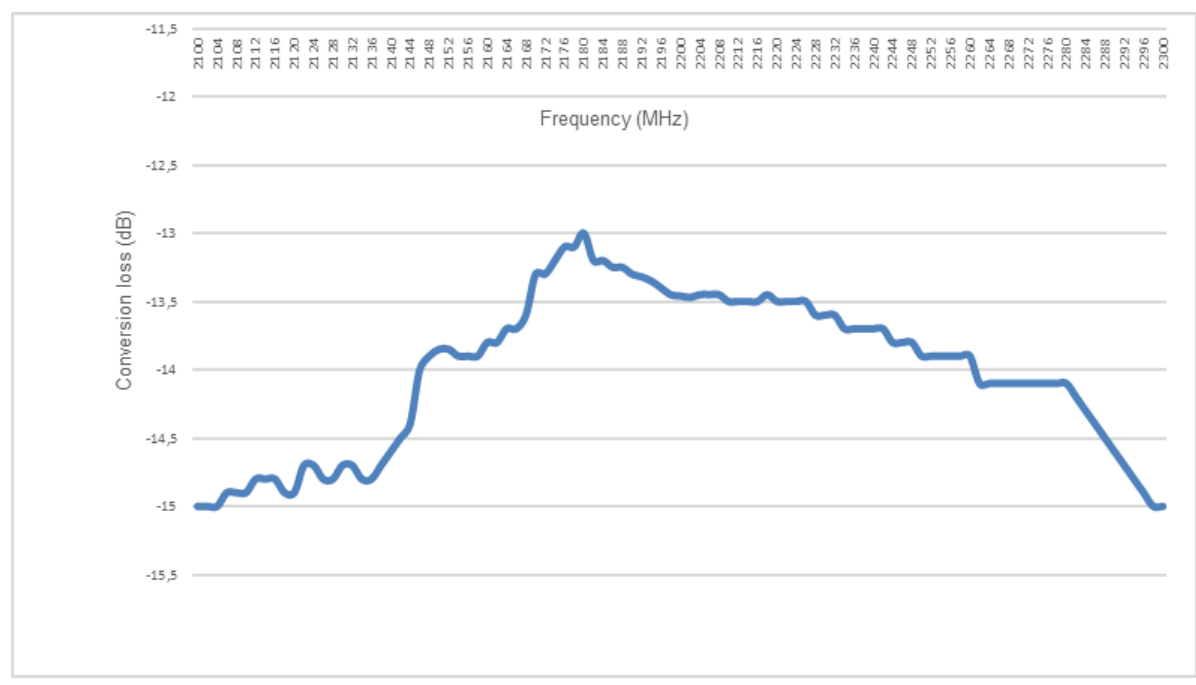

Figure 15. Result of measurement BPSK modulator

\subsection{Frequency synthesizer}

Measurement result of frequency synthesizer were shown in Figures 16 and 17 . We see that relationship between voltage input and frequency output is linearity, power output of frequency is stable. In Figure 16, with input voltage is from 2 voltage to 4.24 voltage, we have output frequency is from $2-2.2 \mathrm{GHz}$ and its power output is over $10 \mathrm{dBm}$ (Figure 17).

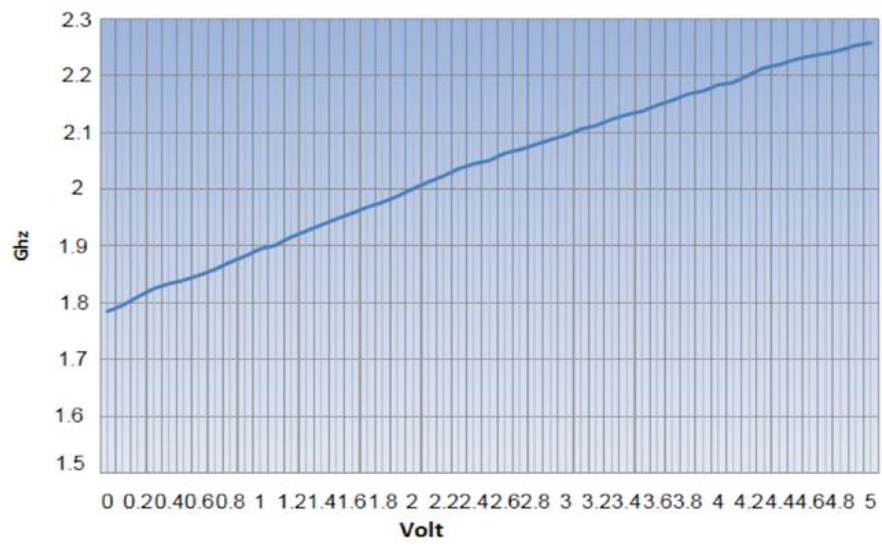

Figure 16. Output frequency and input voltage

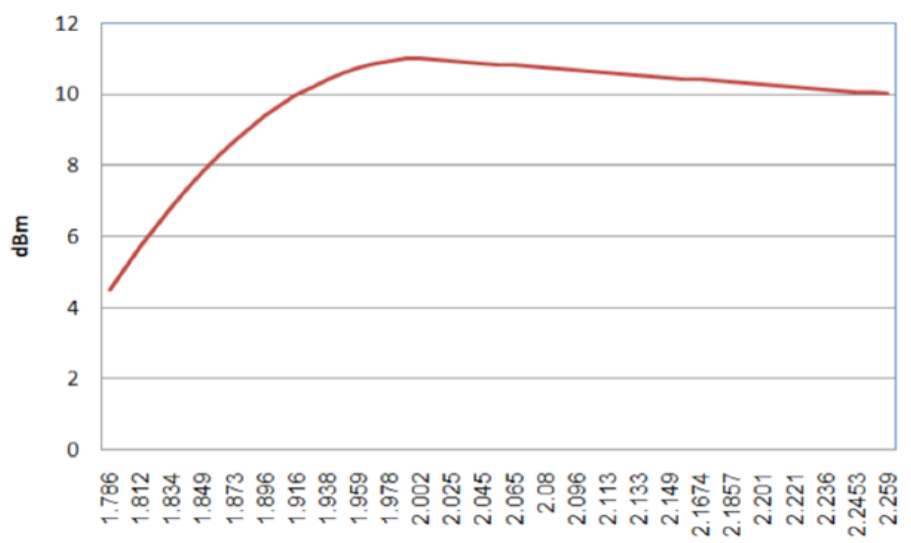

Figure 17. Output frequency and power output 


\subsection{Integrated module}

In this measuring, the setup for measurement consists of an attenuator (20 dB), a generator, a supply power and a network analyser (ESPI test receiver $9 \mathrm{KHz}$ to $3 \mathrm{GHz}$ ). The input amplitude was set at $-14 \mathrm{~dB}$ (weak signal). The power pre-amplifier module was set to work in the AB regime and main power amplifier was set to work in the $\mathrm{C}$ mode. This method helps the transmitter safety work. The Figures 18 and 19 show measurement of integrated module and its result.

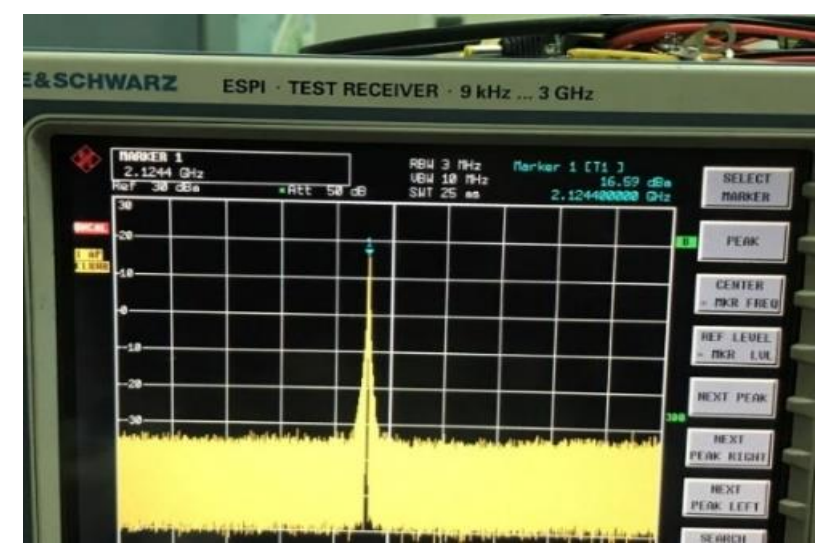

Figure 18. Measurement of integrated module

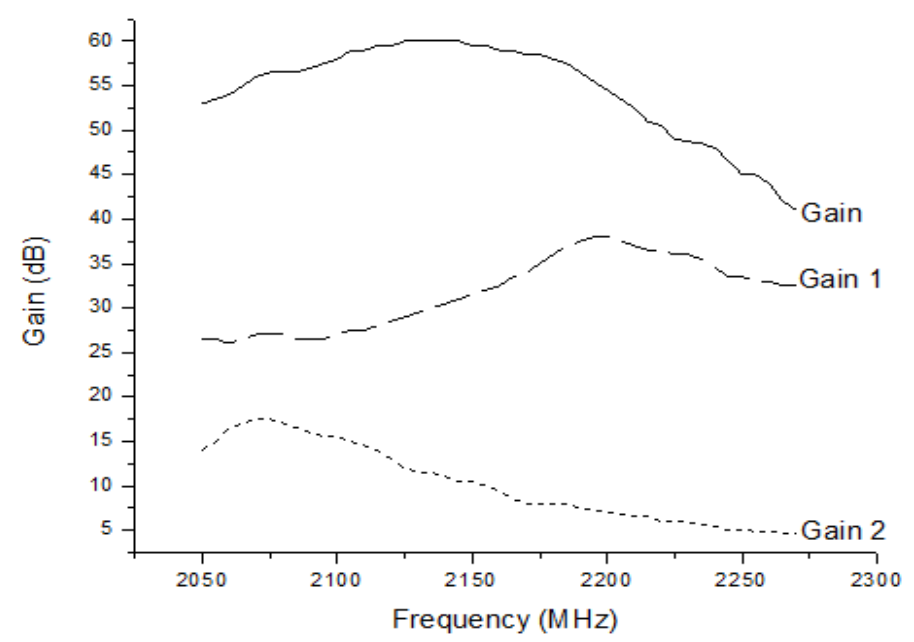

Figure 19. The result of measurement

With result above, we see gain of pre-amplifier stage obtain $18 \mathrm{dBm}$ at $2.065 \mathrm{MHz}$ (Gain 2 line), gain of main amplifier stage obtain $37 \mathrm{dBm}$ at $2.190 \mathrm{MHz}$ (Gain 1 line). Each stage has different peak gain, this result helps research achieved highest power amplifier at center frequency $(2,135 \mathrm{GHz})$. So, gain of module obtain $60 \mathrm{~dB}$ at $2.135 \mathrm{MHz}$, and over $40 \mathrm{~dB}$ in 2.1 to $2.3 \mathrm{GHz}$ frequency range. By designing multistages, using impedance matching, creating multi-peaks, for expand bandwidth purpose. This result satisfies both requirements of the satellite and its ground station.

\section{CONCLUSION}

This paper presented the design and implementation of a transmitter for Nanosatellite in range of 2.1 to $2.3 \mathrm{GHz}$ frequency. The module is new idea for small satellite, because of its structure, physical characteristics, flexibility in working mode of stage and its functions. By using FR4 substrate, multi-peaks in multi-stages power amplifier (two stages used HFET and LDMOS technology), Wilkinson bridge method, PLL structure, suitable devices combined with impedance matching design (in fore-and-aft of module), this 
transmitter responded the requirement of satellite and its ground station segment, such as: power gain $60 \mathrm{~dB}$, low phase noise $-80 \mathrm{dBc} / \mathrm{Hz}$ at $100 \mathrm{Khz}$ offset frequency, wide bandwidth, impedance matching at large frequency range. These results proved that this design is successful. This design can be developed to apply to other systems.

\section{ACKNOWLEDGEMENTS}

Our deep appreciation to Vietnam National Space Center (Vietnam Academy of Science and Technology) and VNU University of Engineering and Technology (Vietnam National University, Hanoi).

\section{REFERENCES}

[1] T. Hiramatsu, S. Shirasaka, and S. Nakasuka, "MicroDragon: a Vietnamese Ocean-observation Microsatellite Based on Hodoyoshi Architecture," In 7th Nano-Satellite Symposium and the 4th UNISEC-Global Meeting, 2016.

[2] M. Ruggieri, "Transmitter model for the design of communication satellites," IEEE Transactions on Aerospace and Electronic Systems, vol. 35, no. 1, pp. 31-42, Jan. 1999, doi: 10.1109/7.745678.

[3] S. L. Chen, S. H. Yu, S. M. Wang, C. F. Chang, and M. H. Shie, "Development of a low cost and high data rate X-band transmitter for micro-satellite applications," In 2017 IEEE Asia Pacific Microwave Conference (APMC), 2017, pp. 1115-1118, doi: 10.1109/APMC.2017.8251651.

[4] H. M. El-Hageen, A. M. Alatwi, and A. Z. Rashed, "Spatial optical transmitter based on on/off keying line coding modulation scheme for optimum performance of telecommunication systems," Indonesian Journal of Electrical Engineering and Computer Science (IJEECS), vol. 21, no. 1, pp. 305-312, Jan. 2021, doi: 10.11591/ijeecs.v21.i1.pp305-312

[5] A. Rafay, S. M. Idrus, K. M. Yusof, and S. H. Mohammad, “A survey on advanced transmission technologies for high bandwidth and good signal quality for hight-speed railways," Indonesian Journal of Electrical Engineering and Computer Science (IJEECS), vol. 23, no. 1, pp. 293-301, Jul. 2021, doi: 10.11591/ijeecs.v23.i1.pp293-301.

[6] H. Y. Lee and S. Y. Shin, "A novel index modulation scheme with impedence matching," Indonesian Journal of Electrical Engineering and Computer Science (IJEECS), vol. 14, no. 3, pp. 1203-1209, Jun. 2019, doi: 10.11591/ijeecs.v14.i3.pp1203-1209.

[7] T. V. Hoi and N. T. Lanh, "Design of high power amplifier based on wilkinson power combiner for wireless communications," Indonesian Journal of Electrical Engineering and Computer Science (IJEECS), vol. 14, no. 3, pp. 1203-1209, Jun. 2019, doi: 10.11591/ijeecs.v23.i1.pp330-337.

[8] T. H. Bui, C. D. Tran, and G. D. Bach, "Design, Fabrication Transmitter Modulator at S band for MicroSatellite with the direct RF input," In 2020 International Conference on Advanced Technologies for Communications (ATC), 2020, pp. 226-230, doi: 10.1109/ATC50776.2020.9255451.

[9] T. H. Bui, C. D. Tran, X. H. Le, and G. D. Bach, "Design and manufacture power pre-amplifier module for transmitter of ground station at S-band," In 2020 IEEE Asia Pacific Conference on Circuits and Systems (APCCAS), 2020, pp. 153-157, doi: 10.1109/APCCAS50809.2020.9301712.

[10] D. T. T. Thuy, V. T. Anh, V. D. Thong, and B. G. Duong, "Research, design and fabrication of a high-power combiner using Wilkinson brighe of L-band," VNU Journal of Science: Mathematics-Physics, vol. 25, pp. 185-189, 2009.

[11] M. Mabrok, Z. Zakaria, T. Sutikno, and A. Alhegazi, "Wideband power amplifier based on Wilkinson power divider for S-band satellite comminucation," Bulletin of Electrical Engineering and Information (BEEI), vol. 8, no. 4, pp. 1531-1536, Dec. 2019, doi: 10.11591/eei.v8i4.1552.

[12] P. Saad, D. Maassen, and G. Boeck, "Efficient and Wideband Two-Stage 100 W GaN-HEMT Power Amplifier," In 2014 9th European Microwave Integrated Circuit Conference, 2014, pp. 337-340, doi: 10.1109/eumic.2014.6997861.

[13] M. S. Khan et al., "A Novel Two-stage Broadband Doherty Power Amplifier for Wireless Application," IEEE Microwave and Wireless Components Letters, vol. 28, no. 1, pp. 40-42, 2018, doi: 10.1109/LMWC.2017.2775157.

[14] S. Bhardwaj and J. Kitchen, "Broadband Paralled Doherty Power Amplifier in GaN for 5G Application," In 2019 IEEE Topical Conference on RF/Microwave Power Amplifier for Radio and Wireless Application (PAWR), May. 2019, pp. 1-3, doi: 10.1109/PAWR.2019.8708727.

[15] H. Malik, D. R. Rotake, and M. Mahajan, "Design and Implementation of BPSK Modulator and Demodulator Using Vhdl," IOSR Journal of Electronics and Communication Engineering, vol. 9, no. 3, pp. 98-105, 2014, doi: 10.9790/2834-093498105.

[16] D. Zhang, J. Zhou, H. Cai, and B. Lin, "Design of the high performance RF transmitter for wideband system," In 2017 Sixth AsiaPacific Conference on Antennas and Propagation (APCAP), Jul. 2018, doi: 10.1109/APCAP.2017.8420753.

[17] M. T. I. Badal, M. B. I. Reaz, M. A. S. Bhuiyan, and N. Kamal, "Design Architectures of the 2.4 GHz CMOS Transmitter for RF Devices," 2019 IEEE Microwave Magazine, vol. 20, no. 1, pp. 38-61, doi: 10.1109/MMM.2018.2875607.

[18] H. Amir-Aslanzadeh, E. J. Pankratz, C. Mishra, and E. Sanchez-Sinencio, "Current-reused 2.4-GHz direct-modulation transmitter with on-chip automatic tuning," IEEE Transactions on Very Large Scale Integration (VLSI) Systems, vol. 21, no. 4, pp.732-746, 2013, doi: 10.1109/TVLSI.2012.2190538.

[19] J. Gil et al., "A Fully Integrated Low-Power High-Coexistence 2.4-GHz ZigBee Transceiver for Biomedical and Healthcare Applications," IEEE Transaction on MTT, vol. 62, no. 9, pp. 1879-1889, Sep. 2014, doi: 10.1109/TMTT.2014.2342671.

[20] V. Kopta, R. Thirunarayanan, F. Pengg, E. Le Roux, and C. Enz, "A 2.4-GHz low complexity polar transmiiter using dynamic biasing for IEEE 802.15.6," In 2015 IEEE International Symposium on Circuits and Systems (ISCAS), 2015, pp. 1686-1689, doi: 10.1109/ISCAS.2015.7168976.

[21] M. Mabrok, Z. Zakaria, T. Sutikno, and A. Alhegazi, "Wideband power amplifier based on Wilkinson power divider for s-band satellite communications," Bulletin of Electrical Engineering and Informations (BEEI), vol.8, no.4, December 2019, pp. 1531-1536, doi: 10.11591/eei.v8i4.1552.

[22] S. R. Sahu and A. Y. Deshmukh, "Design of High Efficiency Two Stage Power Amplifier in 0.13 $\mu$ M RF CMOS Technology for 2.4 GHz WLAN," International Journal of VLSI Design \& Communication Systems (VLSICS), vol. 4, no. 4, Aug. 2013, doi: 10.5121/vlsic.2013.4404.

[23] S. Baek, H. Ryu, I. Nam, M. Jeong, B. E. Kim, and O. Lee, "A 2.4 GHz CMOS Power Amplifier with Paralled-Combined Transistors and Selective Adaptive Biasing for Wireless LAN Applications," Microwave and Optical Technology Letters, vol. 58, no. 6, pp. 1374-1377, 2016. 
[24] O. Ceylan, Y. Kurt, F. A.Tunc, H. B. Yagci, and A. R. Aslan, "Low cost S band communication System Design for Nano Satellites," In Proceedings of 5th International Conference on Recent Advances in Space Technologies-RAST2011, 2011, pp. 767-770, doi: 10.1109/RAST.2011.5966945.

[25] Peiman Aliparast, Member, IEEE, Mahmoud Talafi Noghani, "Design RF Power Amplifier Based on HMIC Technology for Nano-Satellite Communication," In 2019 IEEE 5th International Conference on Knowledge-Based Engineering and Innovation (KBEI), Mar. 2019.

\section{BIOGRAPHIES OF AUTHORS}
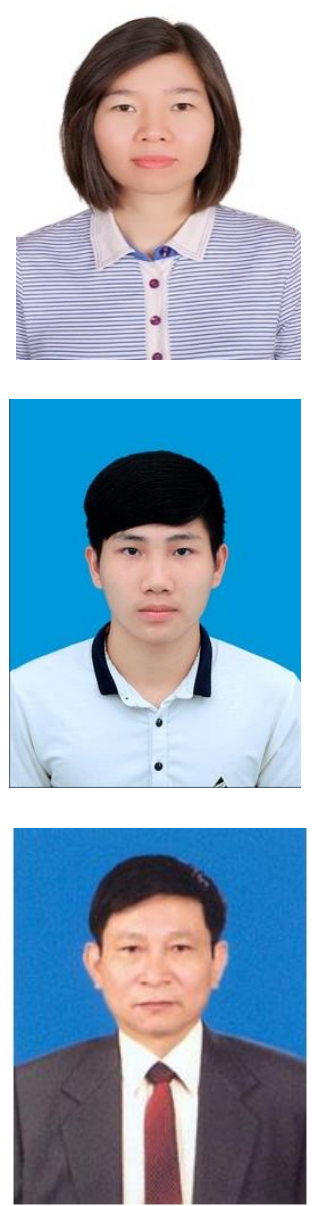

Bui Thi Ha (iD SC SC was born in Hanoi city, Vietnam. She received a Bachelor of Electronic Technology and Education in Hung Yen University of Technology and Education in 2009. She obtained a Master's degree in Electronics Technology and Communication in University of Engineering and Technology, VietNam National University in 2013. She received a Master's System Engineering in System Design Management in Keio University (Tokyo, Japan) in 2016. Since 2013, she has been working at Vietnam National Space Center (VNSC). She research and development satellite system. She can be contacted at email: btha@vnsc.org.vn.

Tran Chinh Doan (iD 81 SC P was born in Nam Dinh Province, Vietnam, in 1997. He received the B.S degree in 2020 and is currently pursuing the MS degree in the faculty of electronics and telecommunications (FET) from University of Engineering and Technology, Vietnam National University, Hanoi (UET-VNU). His current research interests include RF analog signal processing, RF design and RF integrated circuits. He can be contacted at email: chinhdoan310@gmail.com.

Bach Gia Duong (iD 8 SC P received the Ph.D. degree in wireless physics from University of Hanoi in 1988. From 1988 to 1990, he was a research assisstant in Leningrad University, Russia. From 1991 to 2005, he was a researcher in academy o fair force. He has been a lecturer and head of electronics and telecommunications center, University of Engineering and Technology, Vietnam National university since 2006. He was promoted to Associate Proffesser in 2009 and to Professor in 2016. His research forcuses on RF analog signal processing, RF chip design, radar engineering and technology, automatic control. He can be contacted at email: duongbg@vnu.edu.vn. 